\title{
The Employment of Listening Teaching Strategies in Elementary Classrooms by Jordanian Arabic Teachers
}

\author{
Mohammed Al-Badawi
}

Assoc. Prof., Zarqa University, Jordan, badawi80_mohammad@yahoo.com

\author{
Abdessalam Aljaafreh \\ Assoc. Prof., Zarqa University, Jordan, abd_salam56@yahoo.com \\ Reda S. Al-Mawdieh \\ Assoc. Prof., Zarqa University, Jordan, radamwdiah@yahoo.com
} classroom situations by Arabic first grade teachers in Jordan from the perspective of their educational supervisors. The population of this study consists of 50 educational supervisors from all directorates of education in Jordan. The data of the present study was primarily collected by means of a questionnaire consisting of 12 items. These items concerned the listening skill. The data was analyzed using a quantitative approach in order to achieve the study objectives. The results of study revealed that the degree of employment of the listening skill was weak. Moreover, there was no significant statistical difference due to the region and experience variables. The study provided some recommendations stressing the importance of listening skill especially at elementary level. It also recommends that the Jordanian Ministry of Education should give first grade Arabic teachers' vocational training on the teaching of listening.

Keywords: degree of employment; language skills, educational supervisions, listening skill, teachers' evaluation

\section{INTRODUCTION}

Language skills are considered an important pillar of teaching and learning in the different educational stages, through which learners absorb their cultural, social and scientific knowledge. The concern towards improving these skills has been increasing because they represent the basis for educational and behavioural aspects of life. Modern pedagogy stresses the importance of developing educators' language skills that would enable them to use language in everyday life. It is also important to point out here that the relationship between the four language skills is complementary i.e. one language 
skill depends on the other. For instance, speaking depends on listening and reading depends on listening and speaking and writing depends on the three other language skills.

The importance of teaching listening in the context of second and foreign language learning is well-known today in order to achieve language learners' communicative competence. (Morley, 2001), argued that listening was one of the most neglected language skills in situations of second and foreign language teaching until the late 1960s. Richards \& Rodgers, (2001) claim that researchers and language teachers generally paid more attention to reading and grammar than to listening, which was not perceived as a significant feature of language teaching.

From a psychological perspective, Widdowson (2003) views language as a psychological phenomenon that is conceived as a complex epistemic process in the mind, yet it manifests itself externally (physically) in a form of behaviour. The four skills of language share similar mental processes that are behaviourally recognized in linguistic communication. Thus, it is important to adopt a complimentary review in teaching the four skills, especially in the elementary stage.

Generally, teachers in the elementary stage must be a role model with their linguistic performance in the four language skills, because they are expected to set the basis of language in the minds of their learners who are thought to be the future of any society. In other words, the quality of the teachers in the elementary stage will influence the future generation in any society. Khazaali and Momani (2010) claim that if first grade teachers lack competence in some or all of the Arabic language skills in the context of teaching the language, this will produce negative educational outcomes. In a similar context Neild (2003) argued that the quality of educators and teachers is the biggest influence on the learning of the students, if compared with other school factors such as; administration, environment and other school activities. In the Jordanian context, the first grade is officially considered the beginning of this Elementary education.

Many studies have been concerned with the importance of teaching language skills, Ashur and Meqdadi (2016) compared the approaches of teaching Arabic in the past and present in the Arab world. They found that there is a strong tendency among educators and teachers in the present to focus on the language skills; reading, writing, listening and speaking; rather than focusing on the teaching of grammar and dictation.

On the other hand, Alsaqarat (2017) claimed that there is insufficiency of immersion in the home environment for Standard Arabic during the period of language acquisition. Instead he argued for the role of schools as social institutions that play a supportive role especially in elementary stage education to perfect this process. $\mathrm{He}$ states that the employment of modern strategies of teaching Arabic language skills would facilitate and support the learning of language.

In the scope of the facilitating role of language skills, (Pica\&Long.1986, Long\& Adamson. 2012) argue that teaching oral skills (listening and speaking) is considered as half of the process of communication. He adds that the learners gain higher confidence 
with the language when their listening attitudes are positive. This shows that listening should not be considered as an "activity", but it should be taught directly as a skill in its own right. Thus, Joiner $(1986,1997)$ recognizes four approaches that have an effect on the development of listening skill in recent years:

(1) Comprehension based approaches, which encourage a pre-speaking "or silent period" and which claim that listening is the basis for all language development.

(2) Highlighting the receptive skills in general, which have been increasing since the early 1980s.

(3) The spread of functional national approaches and concepts, with their focus on promoting an interest in the utilization of real time material for listening and reading, and emphasizing communicative skill development. Such real time reading and listening materials, as well as writing activities (in a Communicative Curriculum) which include analysis and interaction of texts, give adult learners more chance to engage in challenging tasks that are suitable to their level of cognitive maturity.

Wolvin and Coakley (2000) support the view made by Long (1986) above; they state that listening is the most important skill which evolves with the human being from their first moments. It is responsible for the linguistic and cognitive development during the course of his life. AlBashir (2015), states that listening is the first language skill that should be given more attention and focus in any educational system because of its value in influencing the speaking skill and it would have a negative effect on the learner's level of comprehension and cognitive development.

Furthermore the other oral skill i.e. speaking has an immense contribution in the build up of the learners' ability in articulation and expression to maintain themselves socially and to achieve their social needs. Dockrellm (2012) also stressed the need to learn speaking and listening just before the written skills (reading and writing). The researcher claims that this might help learners to achieve better competence in the written skills at different educational levels. However, other researchers found that if teachers do not provide their students with adequate opportunities for speaking inside the classroom, this will lead to suppressing their thinking ability and the development of their vocabulary (mental lexicon).

Moving to the written form of language skills, it would be good to begin with the reading skill which has been considered as the first gate for the learners to get in touch with knowledge. The skill is important because it equips learners with the ability to acquire knowledge from different sources. Byrnes (1985: 78) and Barnett (1989: 2) state that reading is considered as a source of "comprehensible input". Thus, reading is valued in the communicative classroom teaching, especially when dependable materials can serve the twin purpose of developing reading skills and of nurturing cultural perspectives and indulgence. Barnett (ibid) lists other causes for counting reading skill development as an imperative part of language teaching curriculum; first, reading is indispensable in the teaching of literature, which remains a key goal in many programs. Second, it is a skill that can be maintained after students complete formal language study. Third, it fosters the development and refinement of literacy skills. 
However, writing is the other written-form skill in language. It enables learners to put their utterances and thoughts into written texts. This of course requires a high degree of sophistication and complexity. Thus, writing is seen as the language skill that requires a lot of attention and the adoption of multiple strategies when teaching a language (Rababah and Jamoos (2012).

Al-Batal (2010) reflects on the importance of the listening skill in the context of teaching and learning. He thinks listening is important because teachers and learners spend a lot of time communicating in the language. He states that we spend a lot of time listening to others speak or listening to songs, news, lectures, YouTube, etc. Recent advances in technology have raised the profile of the listening skill in the field of language teaching. In addition, listening provides the required input that can be very important for first language acquisition and second language learning in general and for the development of the speaking skill in particular in both cases. Language teachers need to think of how they can integrate listening into their teaching and provide students with opportunities both inside and outside the classroom to be exposed to significant listening drills.

The present study seeks to evaluate the practices of the present basic stage teachers in the teaching of the listening skill in Jordan. To achieve this goal a review of the previous studies in the field of teaching language skills in general, and listening in particular, was made to help the present researchers get a clear image about the situation of teaching Arabic in Jordan. The paper proceeds explaining the methodology adopted in this research which is quantitative in nature. Then it ends with a discussion of the results and main conclusion remarks.

\section{REVIEW OF RELATED LITERATURE}

Several studies have dealt with the teaching of language skills from different perspectives. However, the emphasis of the present study is on the degree of the employment of female first grade teachers in Jordan to the techniques of teaching the listening skill. Thus, the current researchers reviewed the studies that are relevant to the context of teaching language skills and teaching Arabic, inside and outside of Jordan; for example AlFakeeh (2017) examined the teaching practices of Arabic language skills of 50 university students at the Faculty of Education training as elementary class teachers at Princess Nor Bent Abdul Rahman University in Saudi Arabia. The study revealed that the training teachers showed a high degree of use in their teaching practices to the four language skills in Arabic which is estimated at 4.33 on the study scale.

Al-Khafaifi, (2001) investigated Arabic instructors' attitude at universities in the United States and abroad toward the development of the listening comprehension skill and the techniques they use to improve students' proficiency level in Arabic. The researcher devised a survey to measure the attitude of Arabic instructors at universities in the United States and abroad. The results of the study revealed that Arabic instructors are aware of the importance of teaching listening comprehension in their curricula and they make use of various teaching techniques and resort to extra teaching resources to 
implement the listening tasks. It also indicated that instructors were willing to adopt research findings from other languages in this context for the purposes of improving their teaching performance and the competence of their students.

Abdul Jawad and Qandeel (2015) explored the Arabic teachers' linguistic performance and their attitude towards their job. The study consisted of 65 teachers from the Directorate of Education in eastern and western Gaza. The results revealed that the performance of the teachers reached $70.3 \%$ according to the evaluation made by their supervisors, which is a mediocre performance according to them.

In the same scope, Ikhmeis (2015) conducted a study to examine the effective teaching trends for reading. The study population consisted of 50 female and male first grade teachers in Qweesmeh area in Amman-Jordan. The researchers used an observation card that involved five teaching trends (phonological awareness, phonetics, fluency, vocabulary, and comprehension.) The results of the study showed that generally, old trends in the teaching of reading show high scores in the teachers' teaching practices.

Al-Halak and Almakhzuomi (2012) investigated the skill of recitation at the audio and expressive motor dimension in teaching the reading aloud skill in Arabic. The subjects of this study consisted of 64 elementary stage teachers who were chosen randomly from the Ministry of Education serving in the Directorate of Irbid- Jordan. The study concluded that the teacher's performance at expressive motor level was higher than their performance at the audio level in their teaching of the reading aloud lessons.

Al-Bashir and AlWaeli (2008) investigated that relative weight of speaking (speaking and expression) in the Arabic curriculum in Jordan in the 7th grade. This is achieved by conducting a content analysis of all the specific objectives that are relevant to the evaluation of the speaking skill. The results revealed that there is a significant difference in the evaluation of the relative weight for the speaking skill which has scored highest in contrast with the other language skills.

AlNassar (2005) conducted a study on the teachers' level of performance in the four language skills and it concluded that it is below average. It can be seen that none of the studies discussed above tackled the techniques to teach the listening skill from the point of view of their supervisors and the supervisors' years of experience, which make it different from the previous studies as an indicator to improve teachers' abilities. Thus, the present study focused on the degree of employment of the listening skill in teaching Arabic, taking on board the variables of administrative region of the Ministry of Education (the directorate the teacher serves at), and supervisors' years of experience that may influence the effectiveness of teaching listening.

\section{METHOD}

\section{Statement of the Problem}

Many studies have reported on the low-level achievement of students in Arabic language. (AlMohtadi, Abu Omar, AlHasanat (2017), AlHalaak and AlMakhzoomi (2012), Alshahrani (2012), Zayid (2013)). There is also a lack of attention from Arabic teachers to the listening and speaking skills at school in Jordan. This observation is 
made by one of the researchers in his capacity and experience as a senior supervisor of Arabic at the Ministry of Education in Jordan who has trained and taught hundreds of students and teachers in public and private schools in Jordan and abroad, such as UAE, Saudi Arabia and Oman. Al-Bashir (2005) states that the Arabic curriculum at the Ministry of Education in Jordan does not pay attention to the teaching of listening compared with reading and writing. Anecdotal evidence that is extracted from feedback provided by the teachers of Arabic at the schools supports the view that in practice, the role the school plays in teaching Arabic is limited to the skills of reading and writing.

In their view, the teacher should not attempt to teach Arabic using the listening and speaking skills. This of course goes against the claim that is made by scholars such as Ramanthan and Burning (2012) who maintain that the development of the learners or their achievement level in reading and writing is dependent upon their achievement in the skills of listening and speaking. Thus, this study aims at investigating the degree of employment of female first grade teachers to the teaching strategies of the listening skill at the Ministry of Education in Jordan.

The present study seeks to answer the following research questions

1- To what extent do female Arabic teachers employ teaching the strategies of listening skills in the classroom situations when they teach Arabic from the point of view of their supervisors?

2- Does the administrative region of the Ministry of Education i.e. the administrative directorate in which the teacher and the supervisor serve, influence the supervisors' evaluation of female first grade Arabic teachers in the degree of their employment of the teaching strategies that are related to the listening skill at the level of statistical signification $(\alpha \leq 0.05)$ ?

3- Does the number of years of the supervisors' experience influence their evaluation of female first grade Arabic teachers in the degree of their employment of the teaching strategies that are related to the listening skill at the level of statistical signification $(\alpha \leq 0.05)$ ?

\section{Significance of the Study}

Few studies have tackled the degree of employing the teaching strategies of the female first grade teachers of the listening skill in teaching Arabic in Jordan. The study is also important because of two reasons. First, it might draw the attention of Arabic language supervisors to evaluate the teachers' performance in Arabic language teaching at the elementary stage using the listening skill, without being limited to the teaching of the skill of reading and writing - as is the situation at the present time. Second, it might help Arabic curriculum designers to include more drills and activities that will develop the learners' competence in the four language skills on the basis of the listening skill.

\section{The Boundaries of the Study}

The study has four types of boundaries; first, the spatial boundary which refers to all of the Directorates' of the Ministry of Education. Second, the population boundary which 
refers to the Arabic supervisors of the elementary stage serving at the Ministry of Education in Jordan. Third, the topic boundary which refers to the degree of employment of the first grade female Arabic teachers to the teaching strategies of the listening skill. The last boundary is the temporal boundary which refers to the time in which the study is being conducted, which is the second semester of the year 2017/2018.

\section{The Procedural Definitions of the Study}

Wherever the following terms are used they are intended to have the following meaning for the procedural purposes of this study:

1- Degree of employment: is the score that is given to the teacher by the Arabic supervisor based on the degree of the teachers' employment of the listening skill and its teaching strategies in accordance with the study scale.

2- Administrative region: Jordan is divided into three administrative regions: the South region, the Central region and the North Region.

3- Arabic supervisors: employees who are assigned by the Ministry of Education to play the role of educational and academic supervision on the female teachers of the first elementary stage, that is from the first grade to the 4th grade.

\section{Population of the Study}

The study population consisted of all the first elementary stage supervisors working in the directorates of the Ministry of Education in Jordan during the year 2017/2018. The number of supervisors is 84 according to the records of the Ministry of Education. Fifty supervisors were selected randomly to make the study sample which is made up of $69 \%$ of the original population to conduct this study. The details about the sample and their distribution according to the variables of the study are shown in Table 1.

Table 1

The Details about the Sample

\begin{tabular}{llll}
\hline Variable & Characteristics of variables & Frequencies & Percentage \\
\hline \multirow{3}{*}{ Region (MOE Directorate) } & North & 13 & $26 \%$ \\
\cline { 2 - 4 } & Central & 20 & $40 \%$ \\
\cline { 2 - 4 } & South & 17 & $34 \%$ \\
\hline Total & & 50 & $100 \%$ \\
\hline $\begin{array}{l}\text { Years of experience as an } \\
\text { educational supervisor }\end{array}$ & Less than 10 years & 19 & $38 \%$ \\
\cline { 2 - 4 } Total & More than 10 years & 31 & $62 \%$ \\
\hline Total & & 50 & $100 \%$ \\
\hline
\end{tabular}

\section{Tools of the Study or the Study Scales}

The present researchers developed a scale for measuring the degree of first grade female teachers' employment of listening skill and its teaching strategies from the perspective of their supervisors. This is done by assigning a group of 12 relevant teaching strategies that are measured on a 5 'Degree' Lickert scale response with the following values; 5 very strong, 4 strong, 3 average, 2 weak, 1 very weak. Furthermore, the degree of 
teachers' employment was classified statistically into three levels: (high, medium, and low) this is done by dividing the range of response scale 1-5 into three levels: $1-2.33$, (low), 2.34-3.67 (medium) and 3.68-5 (high).

\section{The Validity of the Research Tool}

In order to check the validity of the research tool, the current researchers got it verified by 9 academic referees specialized in the methods of teaching Arabic working at different universities in Jordan. In addition, to primary stage supervisors and some experienced female teachers of the first grade. The academic referees were asked to check the tools' wording for clarity and its relevance to the strategies of teaching listening. They were also given the freedom to modify anything they see appropriate. The present researchers adopted the referees' feedback with the agreement of $50 \%$ of the referees.

\section{Reliability of the Research Tool}

The present researchers implemented the tool on an extraneous sample that consisted of 20 supervisors where Cronpach's Alpha equation was used in order to check the stability coefficient and to find the degree of internal consistency. The results revealed that the stability coefficient values of the listening skill ranged from $0.90-0.78$ and the total stability coefficient for all the skills was 0.85 , which is a suitable value to achieve the objective of this study.

\section{Data Analysis Procedures}

The following statistical analyses were conducted in order to answer study questions; means find percentages for each teaching strategy of the listening skill were calculated. In addition, one 'WORD' ANOVA analysis was used to answer the second and the third study questions.

\section{FINDINGS AND DISCUSSION}

\section{Research Question Number One}

To what extent do female first grade Arabic teachers employ the teaching strategies of the listening skill in the classroom situations when they teach Arabic from the point of view of their supervisors? 
Table 2

Teaching Strategy Related to Listening Skill

\begin{tabular}{|c|c|c|c|}
\hline \multirow{2}{*}{\multicolumn{4}{|c|}{$\begin{array}{l}\text { NO. Items } \\
\text { Teaching strategy related to listening skill... }\end{array}$}} \\
\hline & & & \\
\hline $\begin{array}{l}12 \text { Teacher trains students to extract the targeted phoneme } \\
\text { from the taught word. }\end{array}$ & 2.56 & 1.11 & Medium \\
\hline $\begin{array}{l}8 \text { Teacher trains students on listening to Arabic chants and } \\
\text { Quranic verses. }\end{array}$ & 2.28 & 1.14 & Low \\
\hline $\begin{array}{ll}2 & \text { Teacher trains students on focused listening using } \\
\text { different means. }\end{array}$ & 2.24 & 0.96 & Low \\
\hline $\begin{array}{l}3 \text { Teacher trains students to recognize the different uttered } \\
\text { speech sounds in language. }\end{array}$ & 2.22 & 0.84 & Low \\
\hline $\begin{array}{ll}\text { Teacher makes sure that students provide correct } \\
\text { responses to the listening material they are exposed to }\end{array}$ & 2.22 & 1.02 & Low \\
\hline $\begin{array}{l}1 \text { Teacher draws students' attention to the importance of } \\
\text { listening skill in class. }\end{array}$ & 2.16 & 0.82 & Low \\
\hline $\begin{array}{l}10 \text { Teacher trains students on attentive listening by exposing } \\
\text { them to audio material. }\end{array}$ & 2.16 & 1.04 & Low \\
\hline $\begin{array}{l}6 \text { Teacher trains students to recognize similar and different } \\
\text { speech sounds in language through minimal pairs. }\end{array}$ & 2.14 & 1.03 & Low \\
\hline $\begin{array}{ll}7 \text { Teacher trains students to recognize phonemes } \\
\text { distribution (initially, medially \& finally) in their } \\
\text { listening to words. }\end{array}$ & 2.12 & 0.96 & Low \\
\hline $\begin{array}{l}5 \text { Teacher trains students to recognize word order in } \\
\text { listening sentences }\end{array}$ & 2.04 & 0.90 & Low \\
\hline $\begin{array}{l}11 \text { Teacher trains students on improving their audio memory } \\
\text { through memorization drills }\end{array}$ & 2.2 & 1.03 & Low \\
\hline $\begin{array}{l}9 \text { Teacher trains students on the recognition of natural } \\
\text { sound through listening to onomatopoeic words in } \\
\text { language. }\end{array}$ & 1.96 & 0.92 & Low \\
\hline Total & 2.19 & 0.30 & Low \\
\hline
\end{tabular}

The results of the supervisors' evaluation show that the first grade female teachers' employment of the listening teaching strategies in the teaching of Arabic came to a low degree with (2.19) mean, and (0.30) standard deviation. This result contradicts the results presented in earlier studies such as (AlBashir. 2005, Hawas. 2004, Graham \& Marcao. 2008, Abeljawad \& Qandeel. 2015, AlShahrani. 2012 and AlHalak \& Almakzoumi. 2012) which came to a medium degree. However, it came consistent with other studies such as (Al-Fakeeh. 2017, Khammes. 2015, Afashi. 2013, Alnassar.2005 and Fakeeh. 2009) that revealed a low degree of employment.

With regards to the evaluations of the teaching strategies, table (2) shows that the strategy that scored highest among others was strategy number 12 which is "teachers train students to extract the phoneme from the uttered word". This strategy scored (2.19) mean, and a standard deviation (0.30) in the second place, came teaching strategy number 8 which is "teacher trains students to listen to Quranic verse and Arabic chants" with a mean score of (2.28). The teaching strategy that came in third place is number 
9 which is " teacher trains students on phoneme recognition through onomatopoeic words" with a mean of (1.96) the rest of the teaching strategies scored low except for with a medium rating degree which complies with the results presented by (AlBashir. 2005 \& Graham\& Marcao. 2008). This low result might be justified and explained by the commonly held view among the female teachers of Arabic in the first grade that listening skills need not to be taught at schools but is acquired at home by means of cultural immersion rather than by conscious teaching and by direct instruction. Thus, listening is considered an ignored language skill in the context of teaching Arabic and evaluating students' performance in Arabic language in Jordan. Of course this is seen as a major flaw in the teaching process because listening is considered the basis for the acquisition and teaching of the other language skills.

Furthermore, the adopted teaching strategies for the listening skill were found to be at odds with the principle of gradual learning and moving from the part to the whole i.e. moving from the simple linguistic units of speech sounds and letters, to the more complex linguistic units of words and utterances. Moreover, the low score of teaching strategies can also be attributed to the lack of employment of classroom activities and the teaching aids that complement and help the learners to grasp and acquire the listening tasks in a better way. This result is similar to the results of the study conducted by Hawas, (2004).

Table3

One-Way ANOVA Results of the Influence of Region on the Evaluation of Supervisors to the Female Teachers' Employment of the Teaching Strategies of the Listening Skill

\begin{tabular}{lllllll}
\hline Skill & Region & $\begin{array}{l}\text { Number of } \\
\text { supervisors }\end{array}$ & SD & $\begin{array}{l}\text { Mean } \\
\text { Square }\end{array}$ & F & Sig. \\
\cline { 1 - 5 } Listening & North & 17 & 0.20 & 2.13 & 1.45 & 0.25 \\
\cline { 2 - 5 } & Central & 13 & 0.30 & 2.28 & & \\
\cline { 2 - 5 } & South & 20 & 0.39 & 2.14 & & \\
\hline
\end{tabular}

The results in table 3 reveal that there is no statistical significance at the level of ( $\alpha$ $\geq 0.05$ ) in the estimation of supervisors to female first grade teachers' degree of employment of teaching strategies for the listening skill. This may be justified by the conformity in the training that these supervisors received at the Ministry of Education in Jordan.

Another reason that might have a similar effect is that the female first grade teachers themselves received the same training when they started working at the Ministry of Education in Jordan. This explains the similarity in the results during the evaluation they received from their supervisors regardless of the supervisor's region where the evaluation is conducted.

The third question of the study: Does the number of years of the supervisors' experience influence the supervisors' evaluation of female first grade Arabic teachers in the degree of their employment of the teaching strategies that are related to the listening skill at the level of statistical signification $(\alpha \geq 0.05)$ ? 
Table 4

Supervisors' Years of Experience

\begin{tabular}{lllllll}
\hline Skill & $\begin{array}{l}\text { Supervisors' years } \\
\text { of experience }\end{array}$ & $\begin{array}{l}\text { Number of } \\
\text { supervisors }\end{array}$ & SD & $\begin{array}{l}\text { Mean } \\
\text { Square }\end{array}$ & F & Sig. \\
\hline Listening & Less than 10 years & 19 & 0.35 & 2.18 & 0.045 & 0.833 \\
\cline { 2 - 5 } & More than 10 years & 31 & 0.27 & 2.20 & & \\
\hline
\end{tabular}

Table 4 shows no statistical significance in the presented results at the level $(\alpha \geq 0.05)$ in the estimation of the supervisor degree of the employment of the teaching strategy according the supervisors' number of years of experience. This is again attributed to the similarity in the training they received as supervisors when they were hired by the Ministry of Education and the close similarity qualification type they had. This shows the Ministry of Education in Jordan follows standardized requirements in the process of recruitment.

\section{RECOMMENDATIONS AND CONCLUSION}

In light of the results presented above, it can be concluded that elementary stage teachers should adopt the prescribed teaching strategies for listening in Jordan, because this skill is the basis for the development of other language skills. Secondly, it is recommended that Arabic curriculum authors give the listening skill the required attention when authoring Arabic textbooks in the Jordanian Ministry of Education. Finally, the Ministry of Education should provide elementary stage Arabic teachers in general and first grade Arabic teachers' in particular vocational training on the teaching of listening to make them aware of its strategies and importance in the process of language teaching and language acquisition.

\section{REFERENCES}

Al-Bashir, Akram, Suad (2008). Speech skills, (oral expression) in the Arabic language curriculum for the seventh grade in Jordan. Journal of Pedagogical and Psychological Sciences, 9(2), 255-235.

Al-Bashir, Akram Adel. (2005). The listening skill in the Arabic language curriculum for the second Grade of the basic stage in Jordan, analytical study. Pedagogical Journal, Kuwait, 77, 99 - 127.

Abdul Jawad, I. Qandil, \& Anisa, A. (2015). Evaluation of the linguistic performance of the new Arabic teachers in public education schools and its relation to their attitudes towards the teaching profession. Al-Quds Open University for Pedagogical and Psychological Studies, 3(12), 259-296.

Alex, A., \&Hong. (2004). Oral language across the curriculum K-12. Retrieved from http://www.indiana.edu/ reading/ieo/digests/d107.html.

Al-faaqih, M. (2017). The level of teaching practices for Arabic language skills among female students and teachers at the Faculty of Pedagogical from the point of view of female collaborators teachers and their attitudes toward the teaching profession. Journal of Pedagogical and Psychological Sciences, 25(3), 88-105. 
Al-Makhzoumi, A, \& Nasser, M. (2012). Degree of employment of the Arabic Language for the Skills of declamation in the aloud reading situation of the Basic Stage Students in Jordan. Journal of Damascus University, 28, 446-423.

Al-Saqarat,Khalaf Ali. (2017). The effect of Frank Lehmann's Strategy on Language Achievement and memorizing for first Grade Students. Journal of Arab Universities Union for Research in Higher Education, 37(3), 19-34.

Al-Shahrani, Khalil Bin Muhammad. (2012). Teacher's ability level of first-grade to develop reading skills for their students (Unpublished master thesis). Umm Al Qura University, Saudi Arabia.

Akram, A. (2005). The listening skill in the Arabic language curriculum for the second Grade of the basic stage in Jordan, analytical study. Pedagogical Journal, Kuwait, $V(77), 99-127$.

Ashor, R., \& Miqdadi, M. (2016). Reading and writing skills and its methods in teaching and strategies. Dar Al-Masira- Amman .

Brown, H. (2000). Principles of language learning and teaching. New York: Longman.

Elizabeth, N., \&Lesnick, J. (2003). Placing a highly qualified teacher in every Philadelphia class room. Research for Action. Philadelphia. Retrieved from www.researchforaction.org.

Hana'a Mohamed. (2015). The degree of first-grade teachers' employment of effective teaching strategies of reading skills (Unpublished master thesis). Middle East University, Jordan.

Ibrahim, I., \& Qandil, A. (2015). Evaluation of the linguistic performance of the new Arabic teachers in public education schools and its relation to their attitudes towards the teaching profession. Al-Quds Open University for Pedagogical and Psychological Studies, 12(3), 259-296.

Ibtesam, A. (2013). Improve the linguistic performance of female students and primary school teachers at Princess Nora Bint Abdulrahman University in light of their language needs. Journal of Future of Arab Education- Egypt, 5(83), 143-195.

Kassem,S., \& Momani, A. (2010). Teaching competencies for the teachers of the basic stage in private schools in light of the variables of scientific qualification, level of experience and specialization. Journal of Damascus University of Pedagogical Sciences, 26(3), 553-593.

Khalaf, A. (2017). The effect of Frank Lehmann's Strategy on Language Achievement and memorizing for first Grade Students. Journal of Arab Universities Union for Research in Higher Education, 37(3), 19-34.

Khalil, M. (2012). teacher's Ability level of first-grade to develop reading skills for their students (Unpublished master thesis). Umm Al Qura University, Saudi Arabia 
Lindsay, G., \& Dockrellm, J. (2002). Meeting the needs of children with speech language and communication needs: A critical perspective on inclusion and collaboration. Child Language Teaching and Therapy, 18(2), 91-101.

Long, M. H., \& Adamson, D. (2012). SLA research and arizona's structured English immersion policies. In G. Valdez, \& C. Faltis (Eds.), Implementing educational language policy in Arizona: An examination of legal, historical and current practices in SEI (pp. 39-55). Claverdon, Avon: Multilingual Matters.

Mashaa'l,m, A. (2017). The level of teaching practices for Arabic language skills among female students and teachers at the Faculty of Pedagogical from the point of view of female collaborators teachers and their attitudes toward the teaching profession. Journal of Pedagogical and Psychological Sciences - Islamic University, 25(3),88-105.

Mohamed, H. (2015). The degree of first-grade teachers' employment of effective teaching strategies of reading skills (Unpublished master thesis). Middle East University, Jordan.

Morreale, S. (2000). Guidelines for developing oral communication-Curricula in kindergarten through twelfth grade. Annandale, VA: National Communication Association.

Hawas, N, (2004). Assessment of listening skills among students in the Primary fourth grade (Unpublished master thesis). Suez Canal University.

Neild, R., Useem, E., Travers, E., \& Lesnick, J. (2003). Once and for all: Placing a highly qualified teacher in every Philadelphia classroom. Philadelphia: Research for Action. Retrieved from: ascd.org/publications/educationalleadership/may05/vol62/num08/Supporting-New-Teachers-in-the-City.aspx.

Pica, T., \& Long, M. H. (1986). The linguistic and conversational performance of experienced and inexperienced teachers. In R. R. Day (Ed.), "Talking to learn": Conversation in second language acquisition (pp. 85-98). Rowley, Mass.: Newbury House.

Rababa'a, I., \& Abu Jamous., A. (2012). The impact of the educational program in critical reading in the development of critical reading skills and writing and creative for students in the tenth grade in Jordan. Najah Research Journal, 26(5), 1027-1058.

Ramanathan, H., \& Burning, M. (20012). Oral English skills in classroom in India: Teachers reflect, (ERIC Digest, ED 462870).

Al-Halak, \& Almakhzuomi. (2012). Degree of employment of the Arabic Language for the Skills of declamation in the aloud reading situation of the Basic Stage Students in Jordan. Journal of Damascus University, 28, 446-423.

Sawaan, A. (2009). Essential principles of the communicative approach. Journal of Teaching, 1(1), 2-6. 
Suzanne, G., \& Ernesto, M. (2008). Strategy instruction in listening for lower intermediate learners of French. Language Learning, 58(4), 746-784.

Yousef, N. (2004). Assessment of listening skills among students in the Primary fourth grade (Unpublished master thesis). Suez Canal University.

Widdowson, H. (2003). Linguistics. Oxford: oxford University Press.

Riley, Burrell, A., \& McCallum, B. (2004). Developing the spoken language skills of reception class children in two multicultural, inner-city primary schools. British Educational Research Journal, 30(5), 657-672.

Wolvin, A., \& Coakley, C. (2000). Listening education in the 22nd century. International Journal of Listening, 14, 143-152.

Zayed, I. (2013). The reality of the Arabic language in public and private schools. Second International Conference on Arabic Language, Dubai. 